Karlsruhe Institute of Technology

\title{
Advances in additive manufacturing of fusion materials
}

\section{1st Symposium on Fusion Technology (SOFT2020) 20TH - 25TH SEPTEMBER 2020, virtual edition}

$\underline{\text { Heiko Neuberger }}{ }^{1}$, Francisco A. Hernández ${ }^{1}$, Michael Rieth$^{2}$, Simon Bonk ${ }^{2}$, Ludek Stratil ${ }^{3}$, Oliver Müller ${ }^{4}$, Kai- $^{-}$ Uwe Volker ${ }^{5}$,

${ }^{1}$ Karlsruhe Institute of Technology (KIT), Institute of Neutron Physics and Reactor Technology (INR)

2 Karlsruhe Institute of Technology (KIT), Institute for Applied Materials (IAM)

${ }^{3}$ Institute of Physics of Materials ASCR, Brno, Czech Republic

${ }^{4}$ Hermle Maschinenbau GmbH, Ottobrunn, Germany

5 PHA Werkstofftechnik, Lüdinghausen, Germany 


\section{Advances in additive manufacturing of fusion materials}

1) Introduction

- Institute KIT INR

- Development organization for DEMO Breeder Blanket (BB)

- How to proceed from the ITER TBM towards DEMO BB

2) Additive Manufacturing Technologies

- Brief Overview on technologies for metals, application of:

- Selective Laser Melting $\rightarrow$ BB internal structures

- Cold Spray based AM $\rightarrow$ First Wall

3) Strategy towards full scale BB First Wall

- Within the conceptual phase $\rightarrow$ now - 2024 and beyond

4) Conclusions 


\section{Introduction}

About the Institute for Neutron Physics and Reactor Technology

https://www.inr.kit.edu/index.php

- Active in nuclear safety analysis, system dynamics and experiments

- In Fusion: Neutronics, Near-Plasma component development

- 10 years of experience in fabrication for fusion blankets

- Established a powerful network for key technologies (Industry + research associations)

$\rightarrow \sim 20$ competences combined

$\rightarrow$ Check state of the art / compare to BB specs

$\rightarrow$ identify technological limits towards BB realization

$\rightarrow$ Address development needs

$\rightarrow$ place development contracts to overcome technological limits

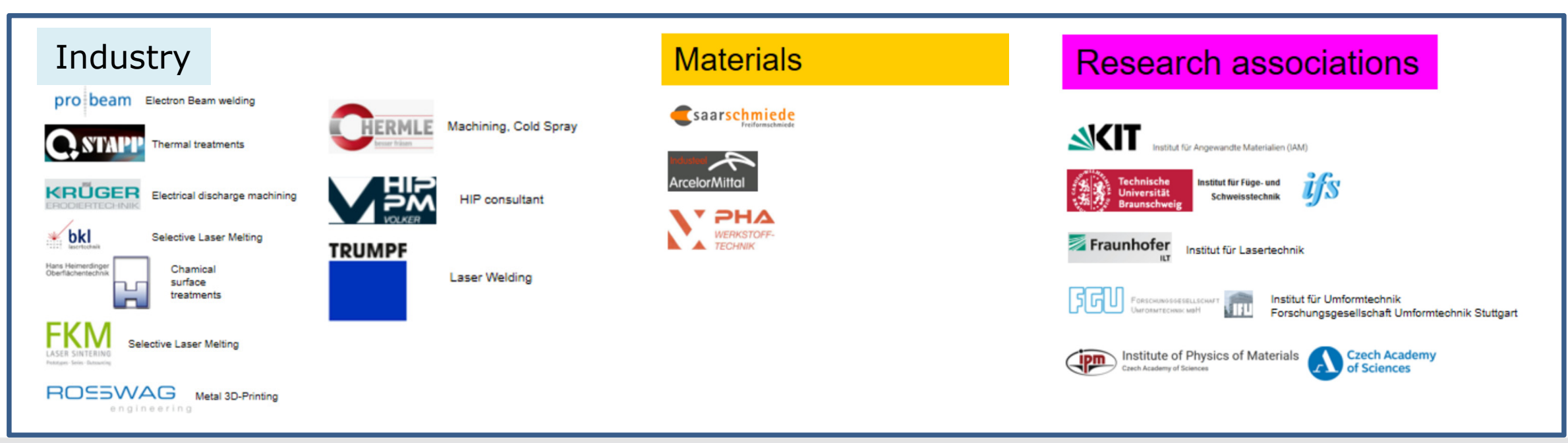


- Address the fabrication developments on sub-component level

$\rightarrow$ Consider welding interfaces between sub-components

$\rightarrow$ Addressed welding within "conventional technologies"

$\rightarrow$ Focus on structural material for HCPB Breeder Blankets, EUROFER

$\rightarrow$ Presently concentrate resources on fabrication First Wall

$\rightarrow$ Most demanding sub-component

- Stay flexible in development, not too focused on details $\rightarrow$ specs evolve and frequently change

- The BB shall be built at reasonable cost + acceptable reliability

- 30 years time horizon $\rightarrow$ for sure needed $\rightarrow$ presently many key issues are not solved

- Important: Keep up do date in manufacturing developments

$\rightarrow$ Therefore we also address Additive Manufacturing since 2015 
State of the art in fabrication of fusion devices reflected by ITER

- First Wall (a) ...

- ... Internal structures e.g. Cooling/Stiffening Plates (b)

- Demonstrated in TBM relevant scale and compatible to conventional technologies

$\rightarrow$ CEA: Machining, Laser and HIP (Reference for ITER)

$\rightarrow$ KIT: Electrical Discharge Machining + Forming + Machining

- manifold and assembly of the TBM box (c) was demonstrated by (CEA)

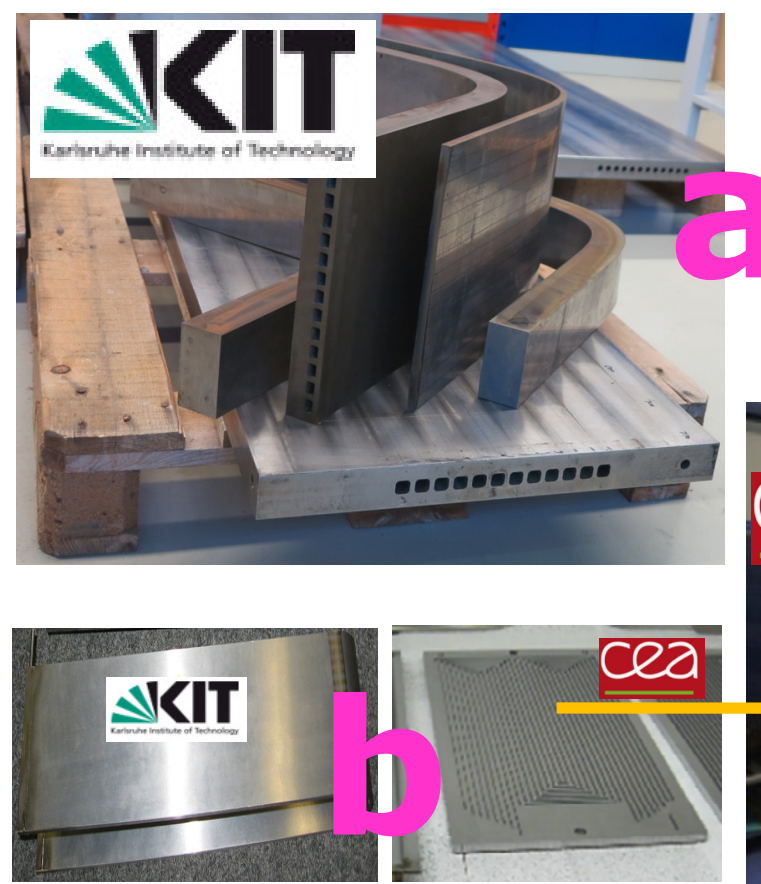

H. Neuberger et al., Evaluation of conservative and Blanket Module and Breeding Blanket First Walls, https://doi.org/10.1016/j.fusengdes.2019.03.124

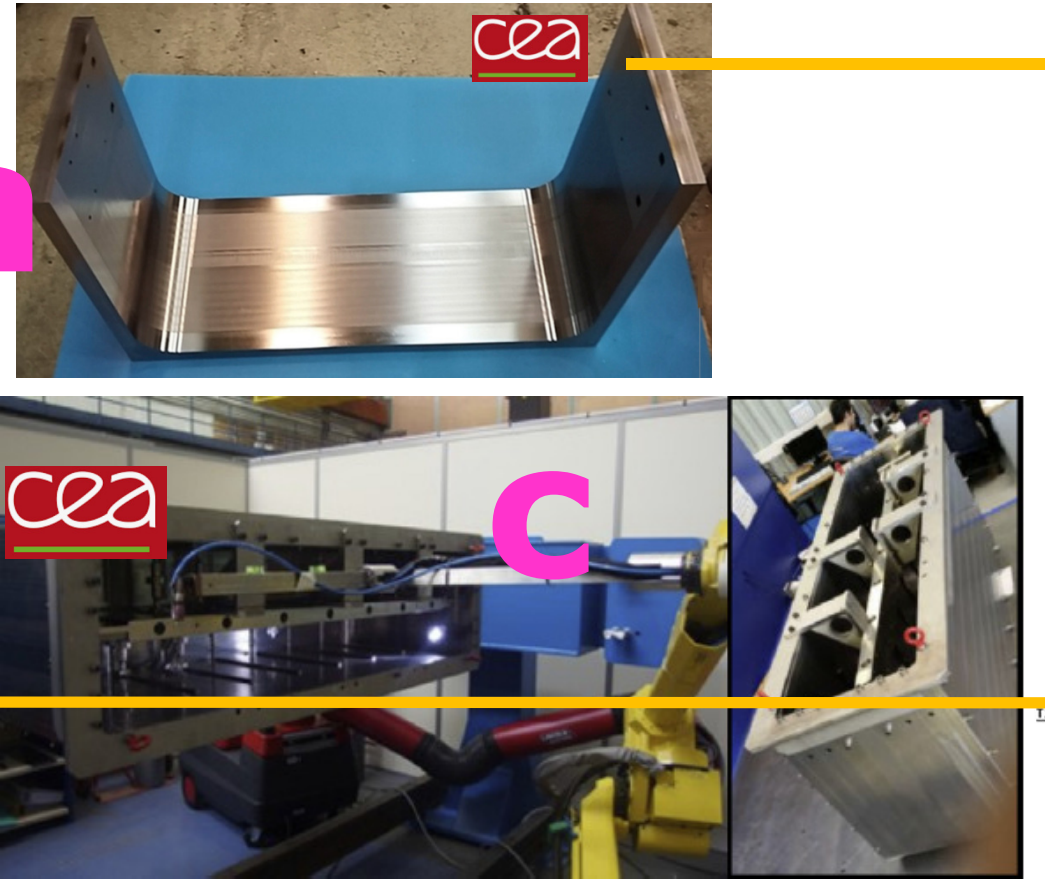

The European ITER Test Blanket Modules: (1) technologies development and qualification, M. 


\section{ITER TBM First Wall vs. DEMO Breeding Blanket First Wall}

- However: wide gap exists in between TBM and DEMO BB fabrication

- Limits in key technologies are reached for TBM, extrapolation not realistic

- Some new solutions are needed

$\rightarrow$ In detail: see comparison of specifications for TBM and BB First Wall

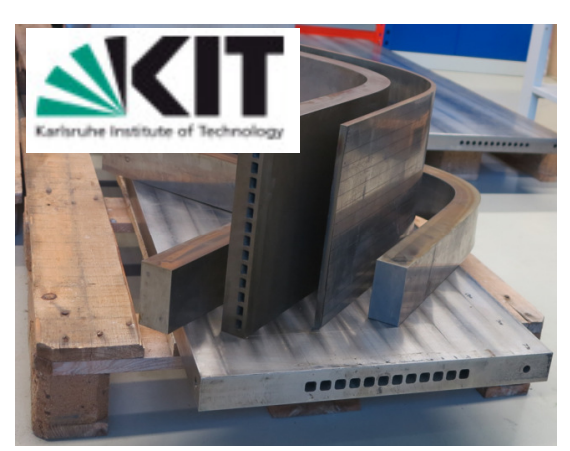

Specifications

BB overall dimensions:

Channels Cross Section (CS):

Structured channels required

(e.g. dimples of semi-detached ribs) ?

Manufacturing cost and procurement:

Existing conv. technologies cover specifications?

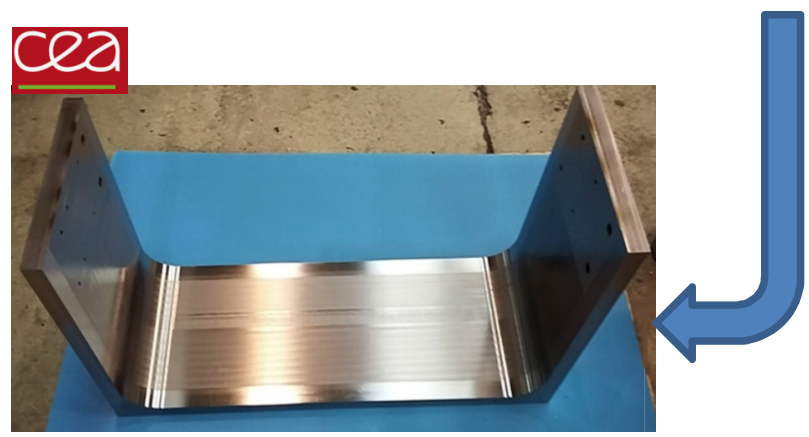

First Wall for Test Blanket Module ITER

$\sim(1.6 \mathrm{~h} \times 0.5 \mathrm{w} \times 1 \mathrm{~d}) \mathrm{m}^{3}$

Channel length: $\sim 2.5 \mathrm{~m}$

U-shaped, 2 bends, plane surface

$\sim 12.5 \times 12.5 \mathrm{~mm}^{2}$

Not mandatory

Only few experimental units procured

Yes, procurement for ITER is launched
First Wall for DEMO Breeder Blanket

$\sim(12 \mathrm{~h} \times 2 \mathrm{w} \times 1 \mathrm{~d}) \mathrm{m}^{3}$ (SMS)

$\sim(2 \mathrm{~h} \times 2 \mathrm{w} \times 1 \mathrm{~d}) \mathrm{m}^{3}$ (MMS)

3D-surface, „roof-top-shape“

comparable CS as TBM

At least locally in some blankets Mass production compatible

No $\rightarrow$ AM may provide options 


\section{Additive Manufacturing Technologies}

\section{What characterizes Additive Manufacturing?}

- Huge diversity of processes / variations exists, no details here

- However: All AM processes have one thing in common:

$\rightarrow$ A product is built by adding material

$\rightarrow$ instead of subtracting material (e.g. machining)

- Material added as powder, wire, solid, ... Deposition energy is provided by Laser, EB, kinetic, ...

- For HCPB BB fabrication: Selected two most developed and promising technologies:

Powder Bed Laser Beam Fusion = Selective Laser Melting (SLM)

$\rightarrow$ Good for thin walled and high complex components

$\rightarrow$ box internal structures

Direct Energy Deposition Cold Spray + machining:

$\rightarrow$ Larger dimensions and deposition rate

$\rightarrow$ less complex structures

$\rightarrow$ selected for First Wall

$\rightarrow 2$ independent development approaches in $2015+2017$ 


\subsection{Selective Laser Melting}

How Selective Laser Melting (SLM) works

- Inside of a process confinement (a) of a SLM machine

- A product (b) is built in slices layer by layer on top of a building platform (c)

- During fabrication the product is fully surrounded in metal powder

- Local solidification is provided by a Laser (d) according to the geometry data of the product

- Details see internet (produces of SLM machines)

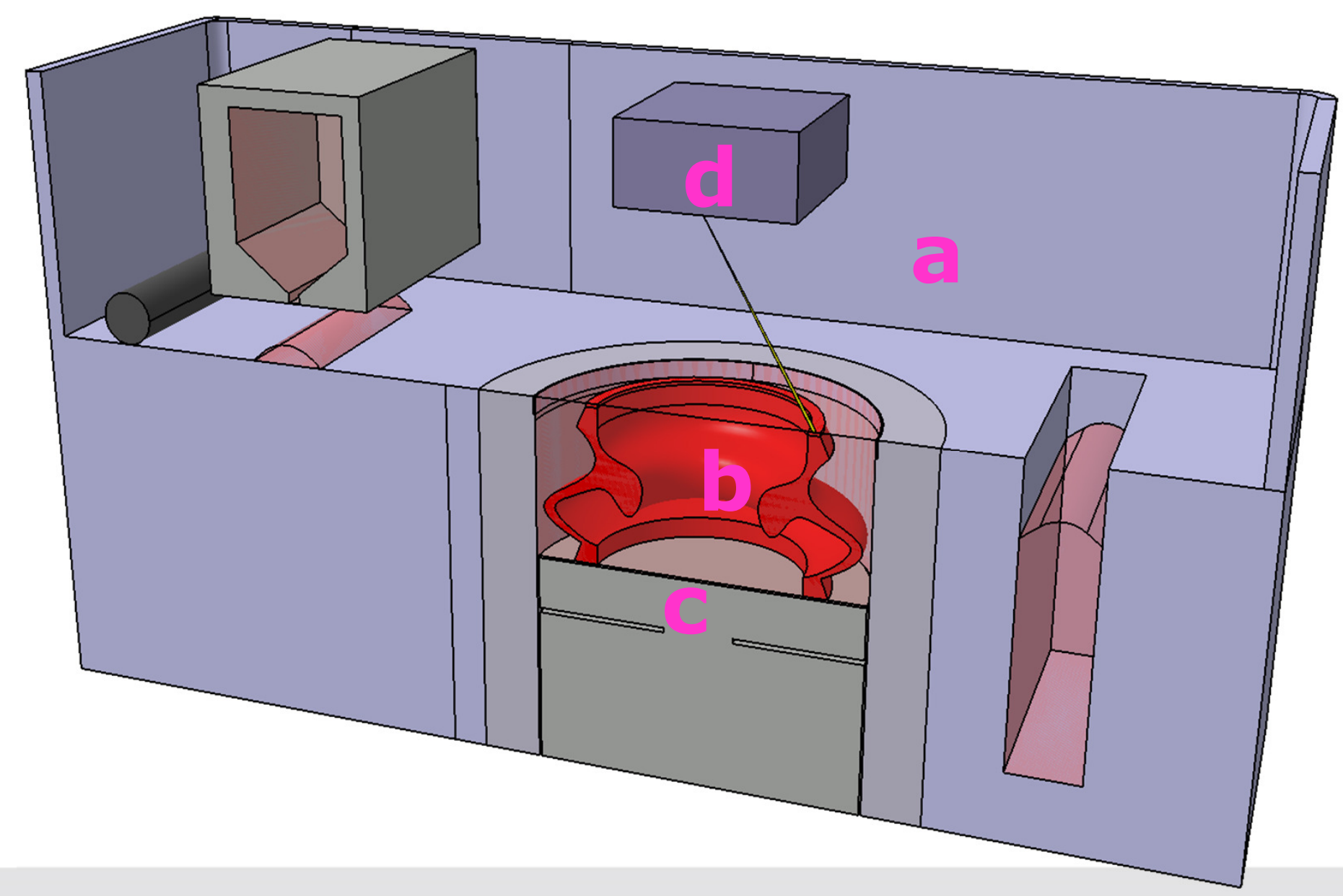




\section{Examples of Selective Laser Melting fabricated test parts}

- Started benchmarking studies among different suppliers

- Ordered EUROFER-like mixed metal powder batches

- Procured demonstration parts with increasing complexity and dimensions

$\rightarrow$ material characterization specimen

$\rightarrow$ thin- and double wall structures

$\rightarrow$ samples with BB relevant cooling channels

$\rightarrow$ Parts to verify numerical distortion prediction tools

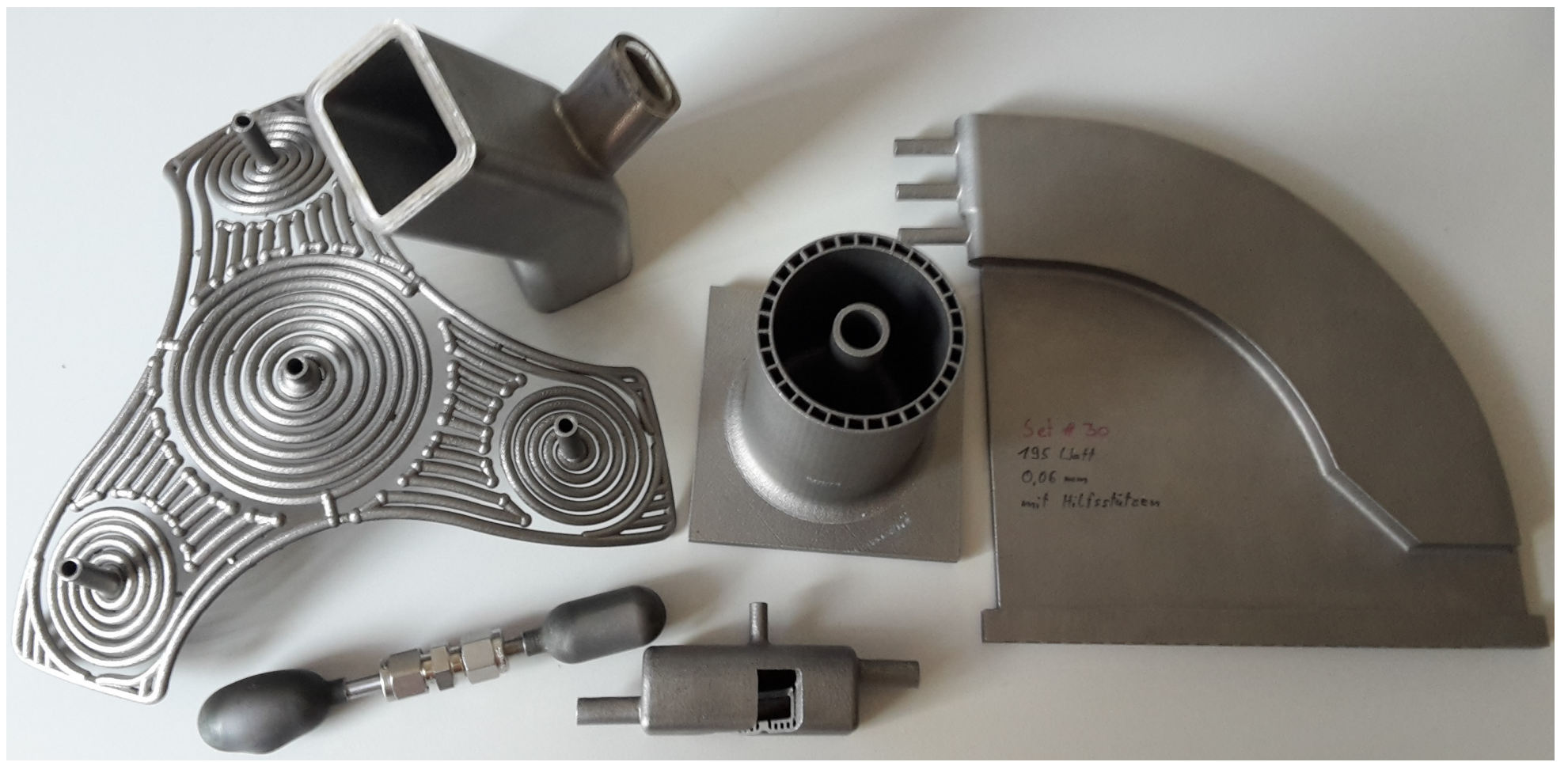




\section{How good are material properties of SLM- compared to conventional EUROFER ?}

- Very Important question, strong interactions with material science

- To obtain tempered martensite post heat treatment after SLM is needed

- To reduce porosity after SLM a HIP cycle is recommended

- The specified chemical composition and a high cleanness of the powder is mandatory

- For detailed results: see papers in material journals, published soon:

$\rightarrow$ M. Rieth: Specific Additive Manufacturing Processes for Nuclear Fusion Applications

$\rightarrow$ L. Stratil: Microstructural and mechanical characterization of EUROFER prepared by LBM

Tensile- and Charpy
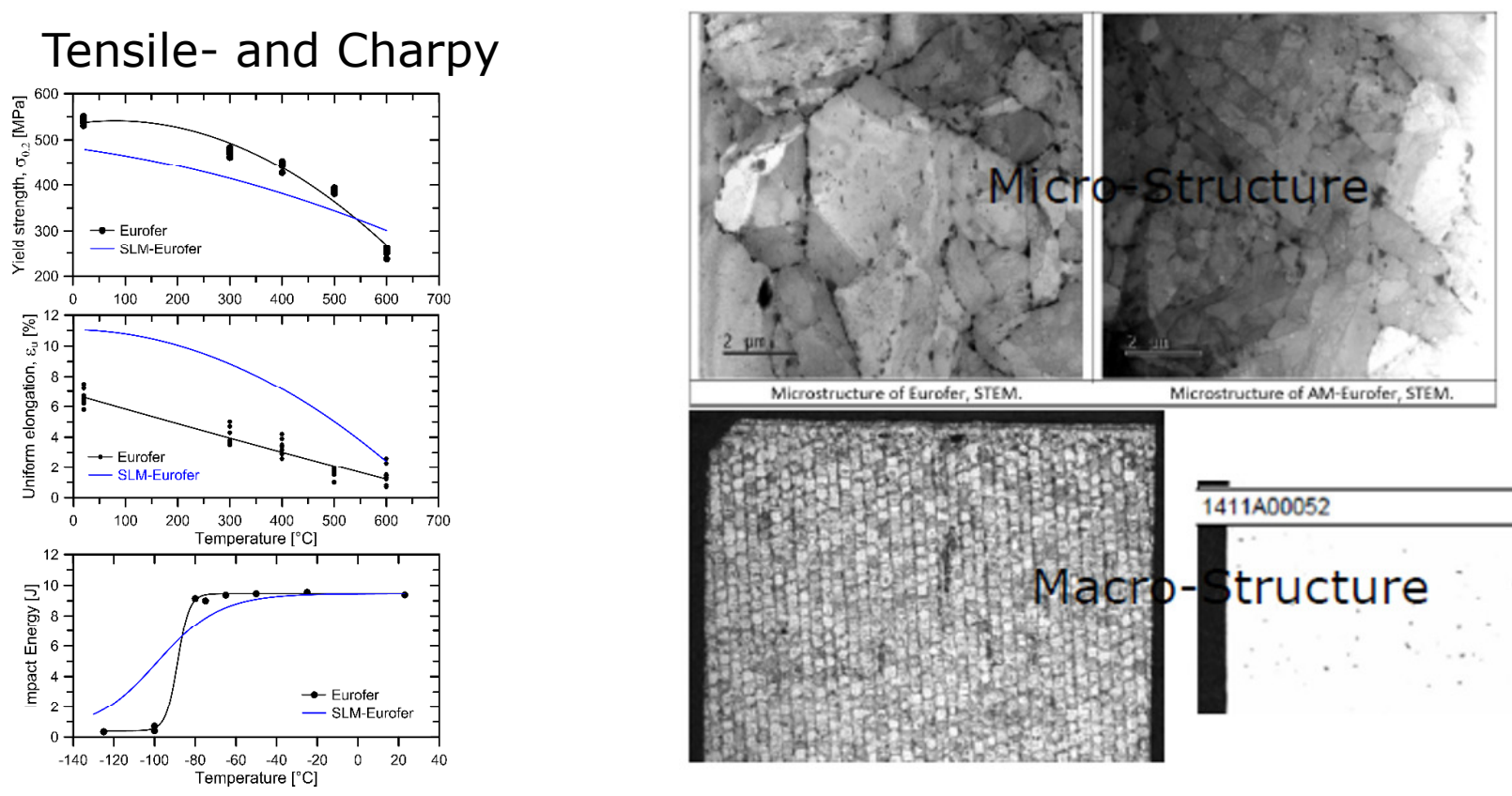

Creep and fatigue

- SLM products demonstrate promising properties close to conventional EUROFER 


\section{Technological limits in SLM: geometry restrictions}

- Not every geometry can be "just built", supports may be needed

- Important to understand reasons: Where and why supports ?

$\rightarrow$ Follow design guidelines

$\rightarrow$ Use assistance by suppliers to improve results

$\rightarrow$ Take into account critical issues already during design

- Examples: angles, geometry of arches, wall thickness, orientation during production ...
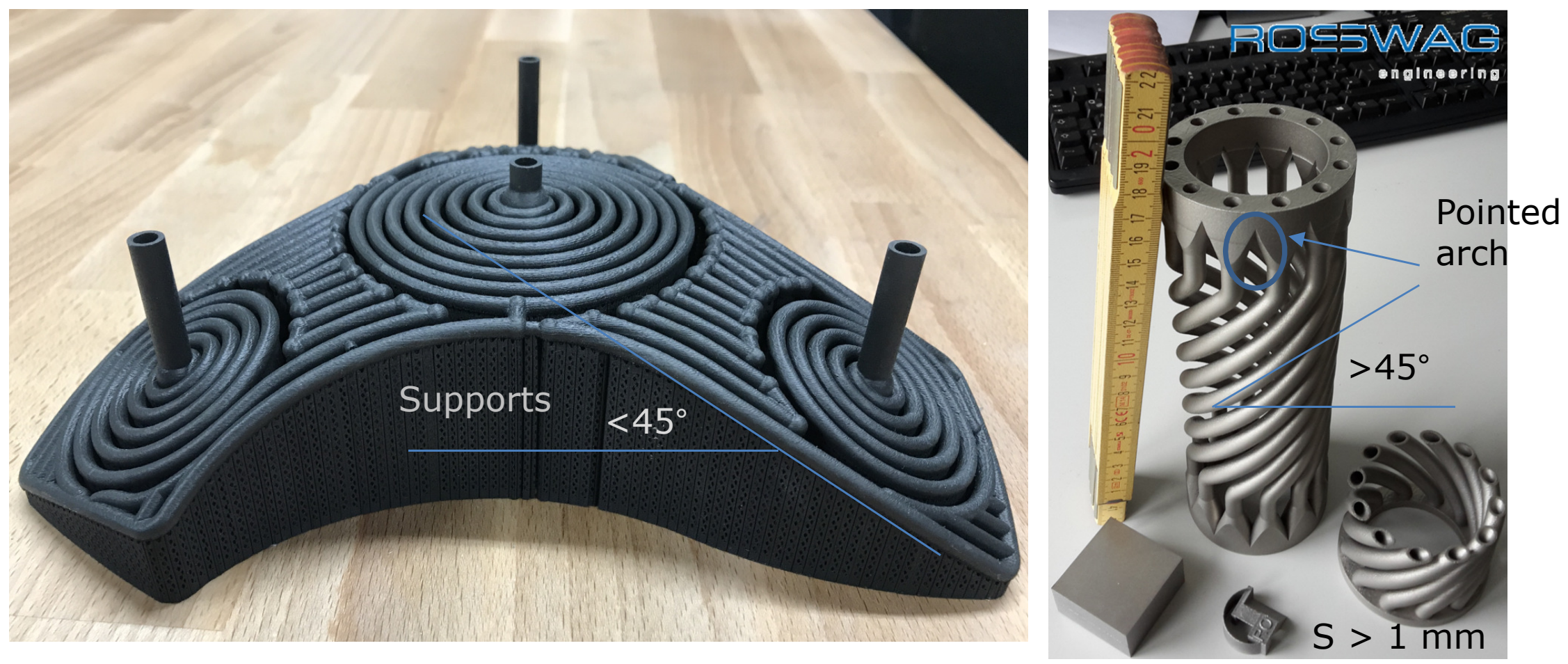


\section{Technological limits in SLM: maximum dimensions}

- Size limits in SLM driven (confinement $\rightarrow$ inert + dust protection)

- Presently max. part dimensions $\sim 500 \times 300 \times 800$, details internet

- Scale up to full dimensions and "print" integral BB not applicable

- However options for expand dimensional limits were developed by KIT (already presented):

$\rightarrow$ Assemble Hybrid Components by welding from SLM-produced + conv. Segments

$\rightarrow$ SLM applied as Continuous production with "printed" confinement chamber extension
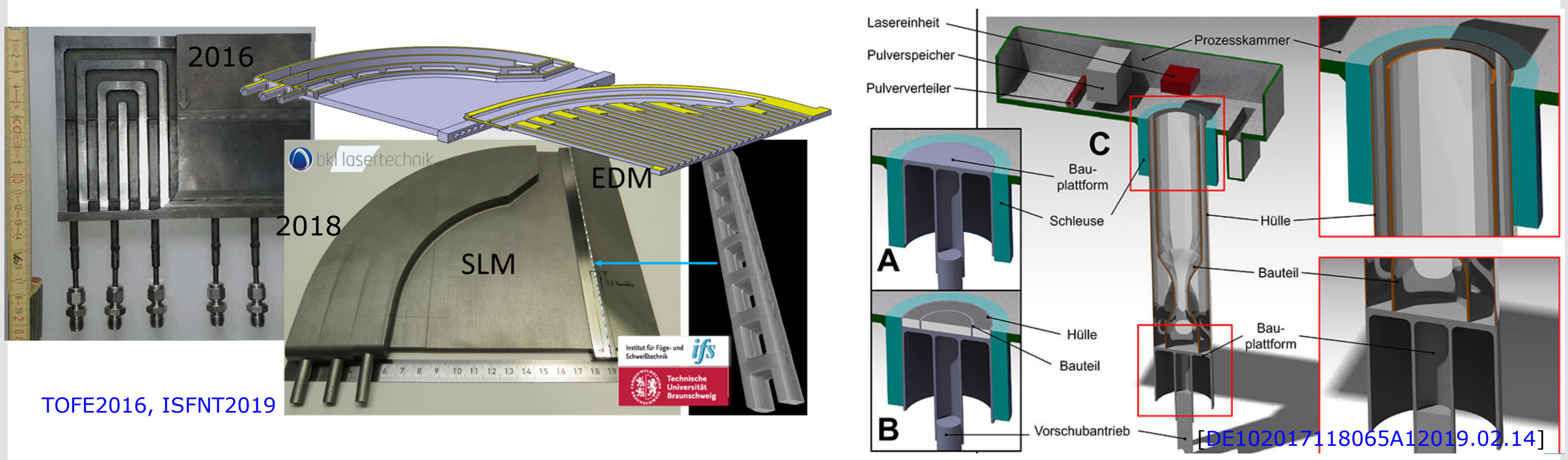


\section{Technological limits in SLM: deformations due to thermal gradients}

- Thermal gradients inside the powder bed lead to deformations:

$\rightarrow$ Important to optimize design + orientation for mitigation

$\rightarrow$ Example: Version 1 vs. Version 2:

$\rightarrow$ Similar part, two orientations, two different results ...
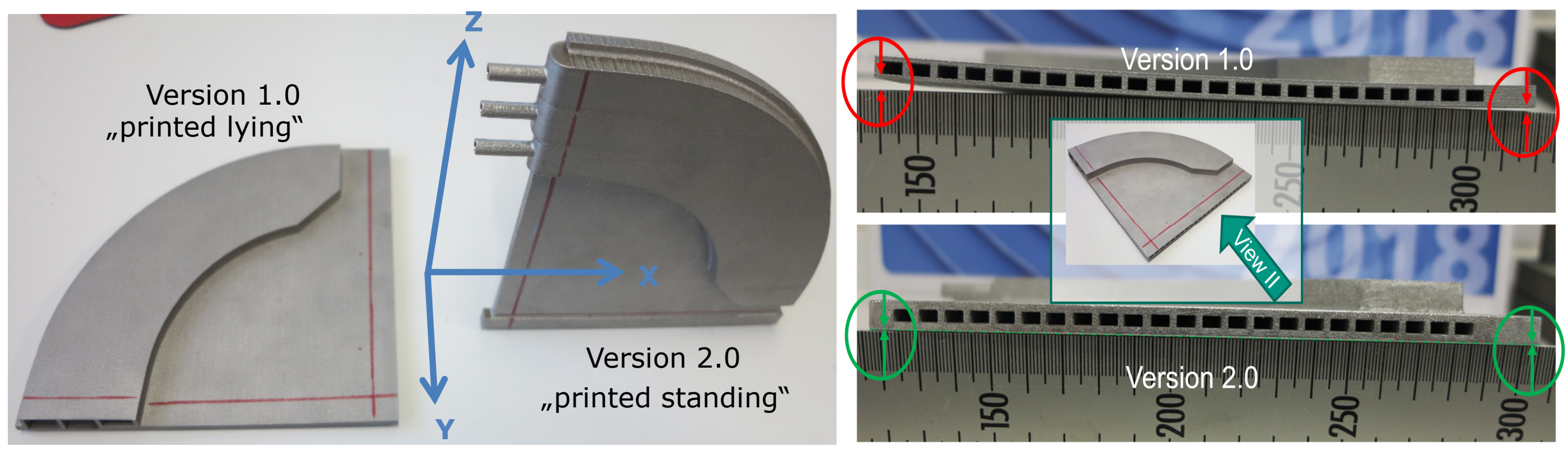

- However production time: version $2 \rightarrow \sim 10 \times$ number of layers, $\sim 3 \times$ production time

- Increasing parts height $\rightarrow$ increasing again thermal gradients in powder bed 


\section{Technological limits in SLM: innovation to mitigate gradients}

- Innovation to mitigate gradients $\rightarrow$ "printed resistive heater coils"

- Possible because $R_{\text {powder }}>>R_{\text {SLM product }}$

- Printed coils are operated as in-situ temperature monitoring and regulation device

- Heater coils (C) placed on feedthroughs (F) on platform (P)

- Better than just heating building platform surface

$\rightarrow$ Now, measurement and regulation inside powder bed

$\rightarrow \mathrm{T}_{\max }$ is in the centre of powder bed (where it should be)

Simple proof of concept experiments conducted, details: please contact...
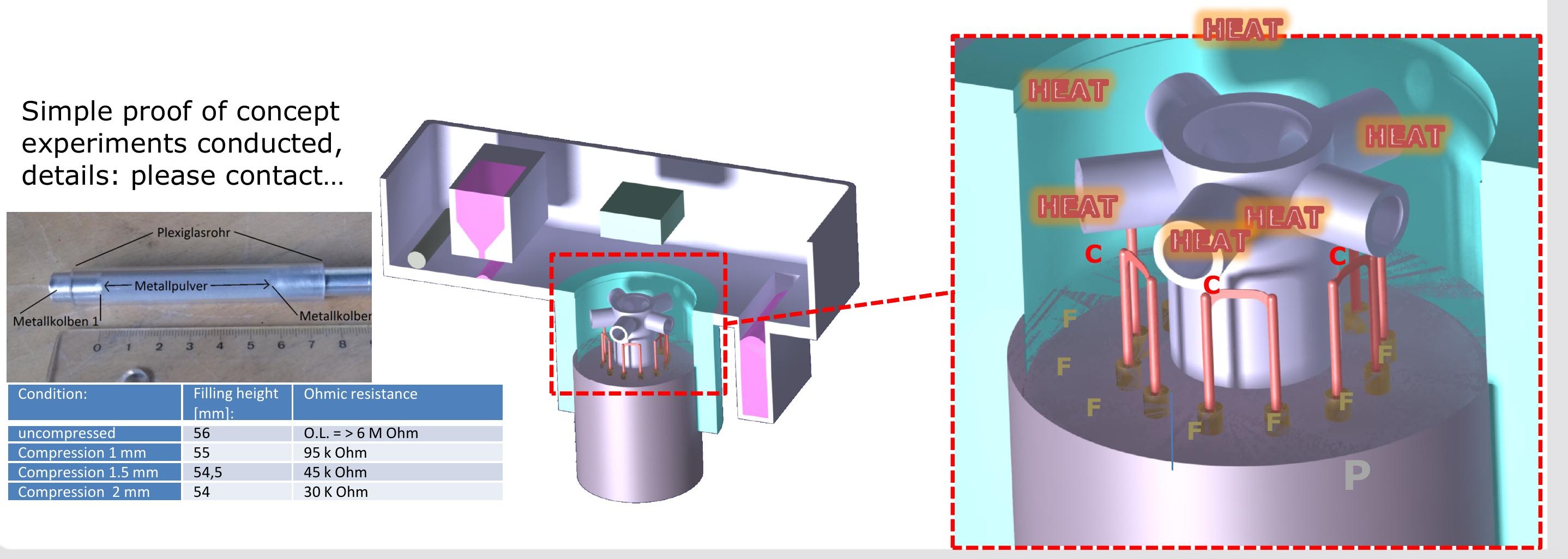


\section{How to continue development for SLM}

- SLM has been demonstrated as goal oriented option

$\rightarrow$ Feasibility of BB relevant internal complex components

$\rightarrow$ Innovations have been developed to overcome limits

- KIT INR: continue to build demonstration and performance testing parts (hybrid components)

- Passing material qualification activity to material science

$\rightarrow$ Qualification and implementation into Codes and Standards

$\rightarrow$ Address irradiation program for SLM processed EUROFER 


\subsection{Cold Spray + machining + HIP}

\section{Cold Spray in combination with machining and HIP}

- $\mathrm{CS}=$ powder deposition via kinetic energy

- Provides option to temporarily fill cavities with non-metallic and water soluble material (process configuration $\rightarrow$ Hermle)

- The integral process chain applied for cooling plate fabrication consists of 6 Steps:
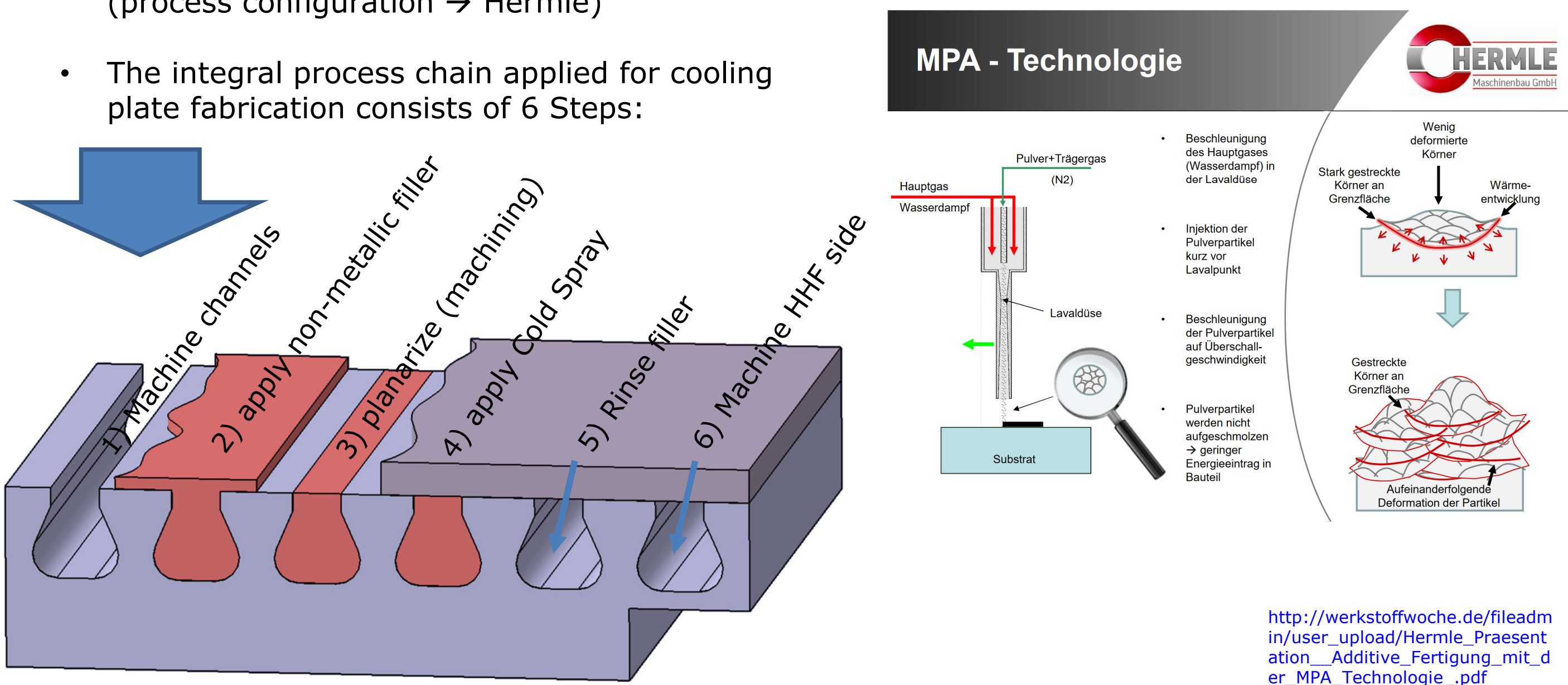


\section{Process configuration customized for BB First Wall application}

- Goal: Simplify licensing by:

$\rightarrow$ Excluding CS deposited material from structural function of the product ... $\rightarrow \ldots$ and use CS only as pressure seal during a HIP weld (a)

$\rightarrow$ HIP weld joins substrate plate to cover plate $\rightarrow$ provides pressure (b) barrier

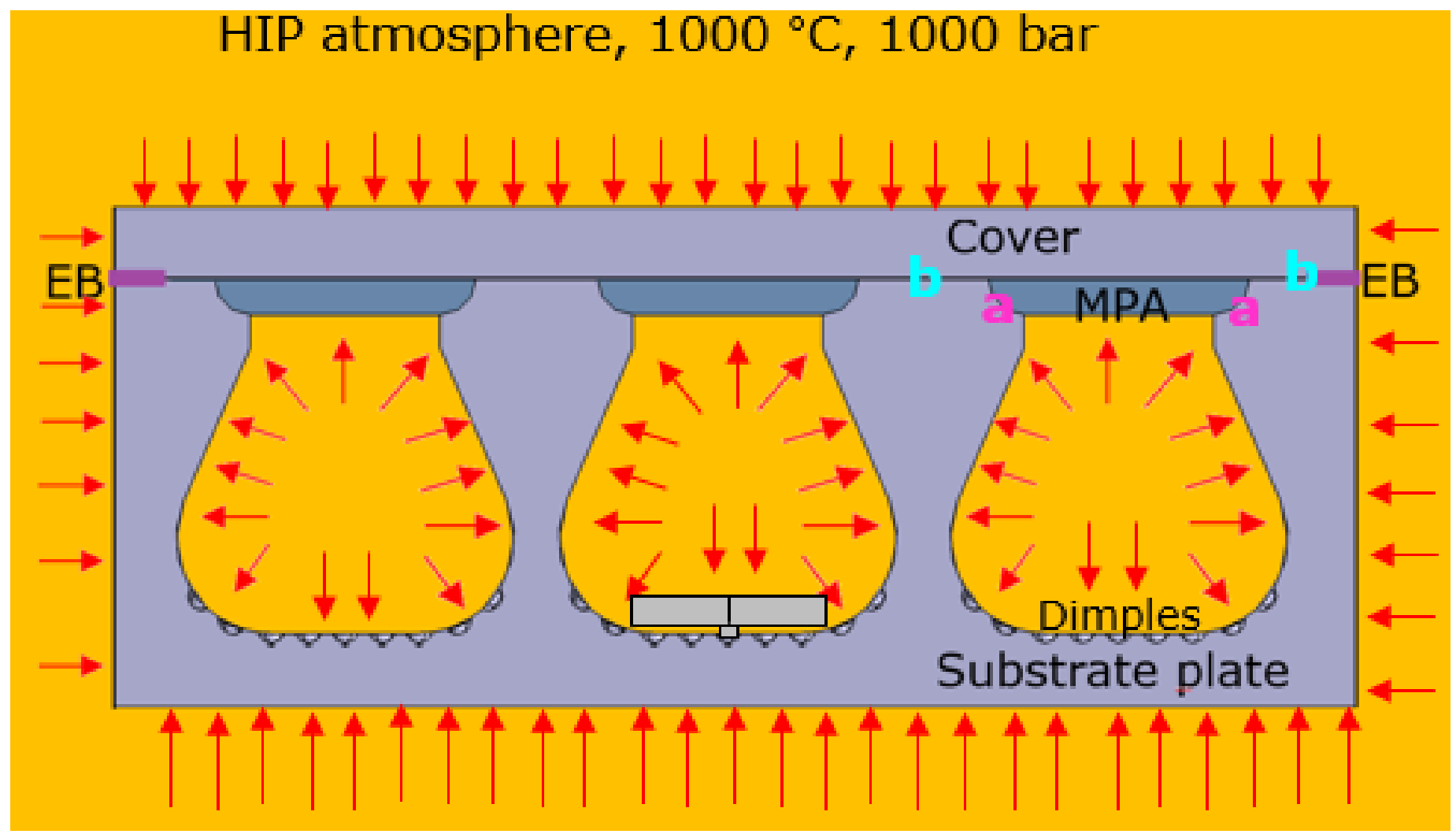




\section{Process configuration customized for BB First Wall application}

- Detailed modifications are

$\rightarrow$ machine additional groove in step 3

$\rightarrow$ introduce one additional planarization by machining $\rightarrow$ step 6

$\rightarrow$ install and join a cover plate by EB (Steps 7) and HIP (Step 8)

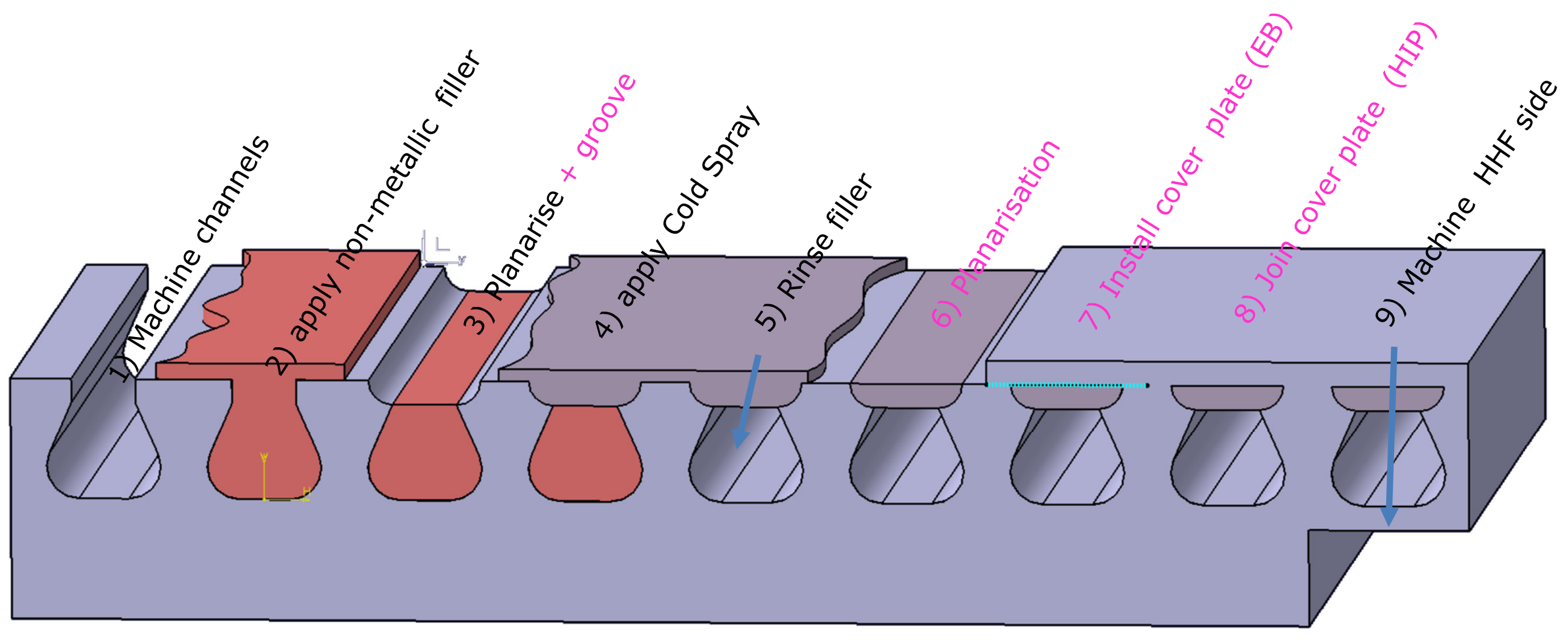


Fabrication experiments results in $\mathbf{2 0 2 0}$

\section{SIKIT}

- Semi-detached V-shaped ribs were firstly demonstrated of inside of a channel

$\rightarrow$ Riveting pins machined on HHF side of the channel

$\rightarrow$ Ribs build by SLM were installed and attached onto pins

$\rightarrow$ Installation time $~ 1 \mathrm{~min} /$ rib "by hand"

$\rightarrow$ Can be automated

$\rightarrow$ Soon tested is hydraulic experiments
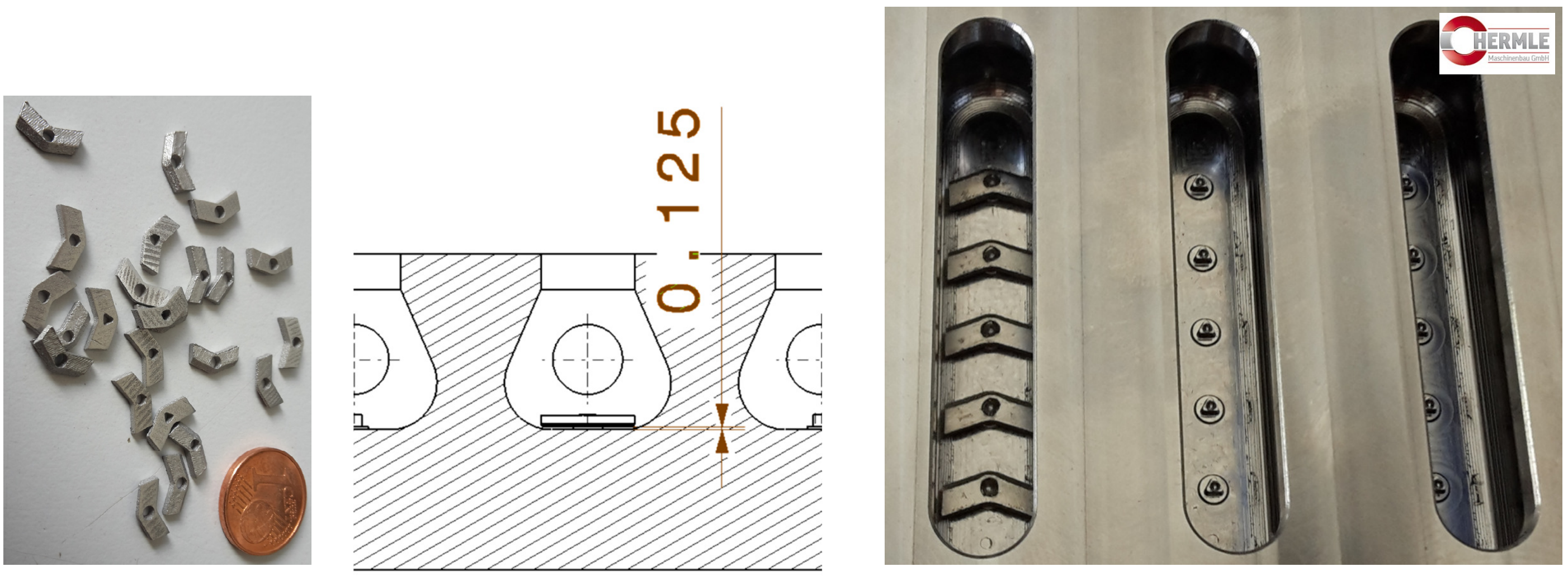
- General improvement of process parameters is ongoing, e.g.:

$\rightarrow$ Optimization of geometry of grooves on top of the filled channels $\rightarrow$ Round edges to improve adhesion between CS and substrate by

$\rightarrow$ Improvement is verifies by Destructive Examination presently
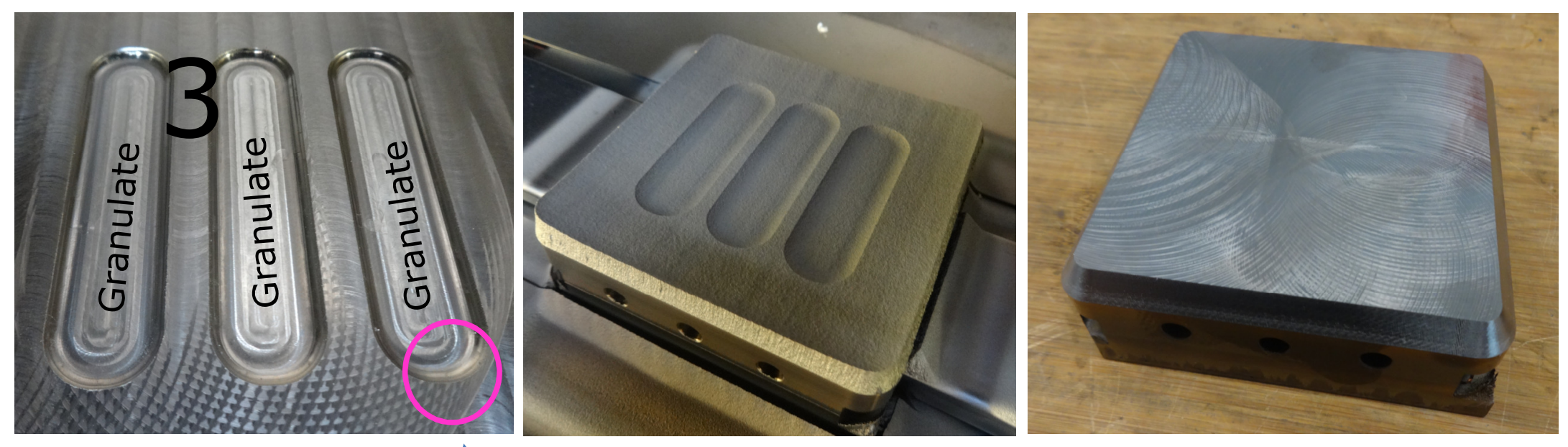

1

Substrate plate with rounded edges with temporarily filled cavities before...

...during and ...

...after Cold Spray deposition 
- Experiments to optimize planarization and

- preparation of HIP-welding ...

This is where we are now... Lost some weeks due to CORONA Step will be completed (hopefully) by end of $2020 \rightarrow$

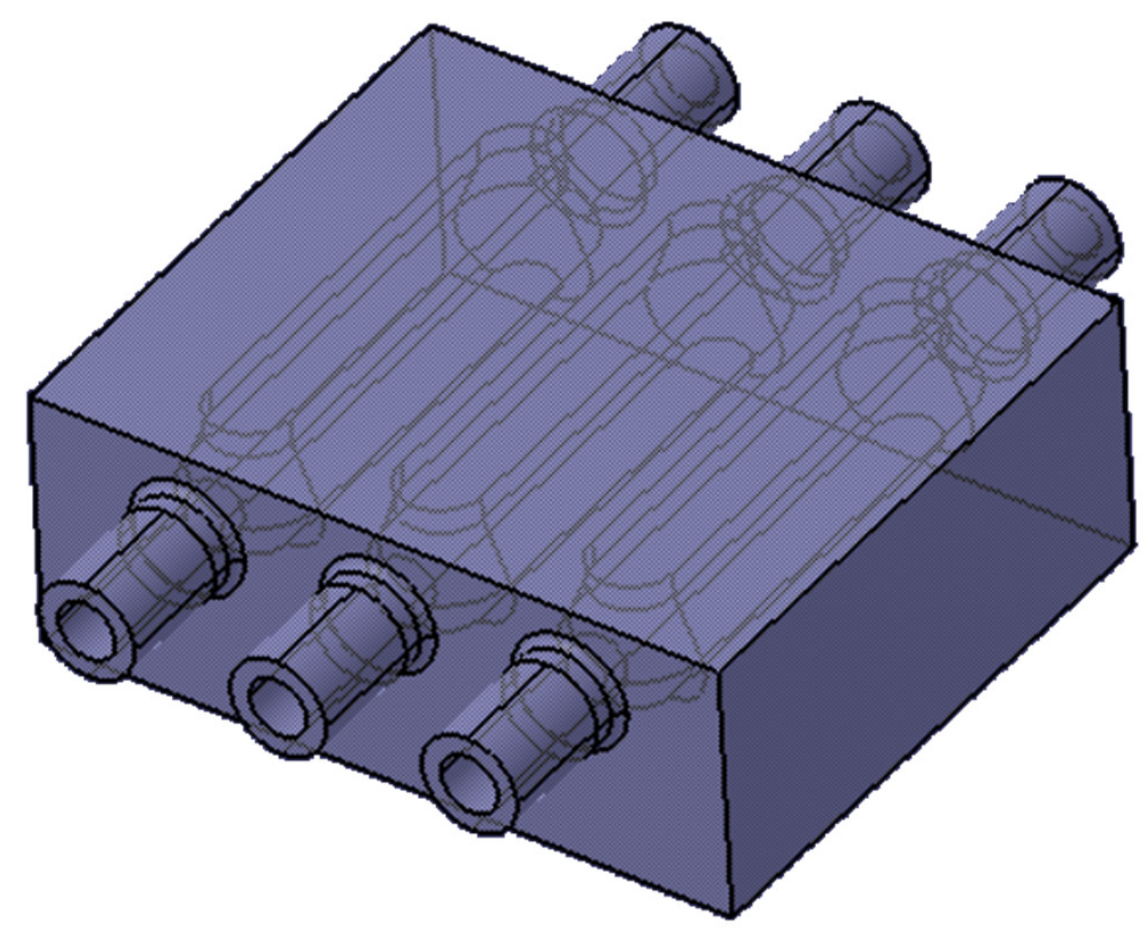

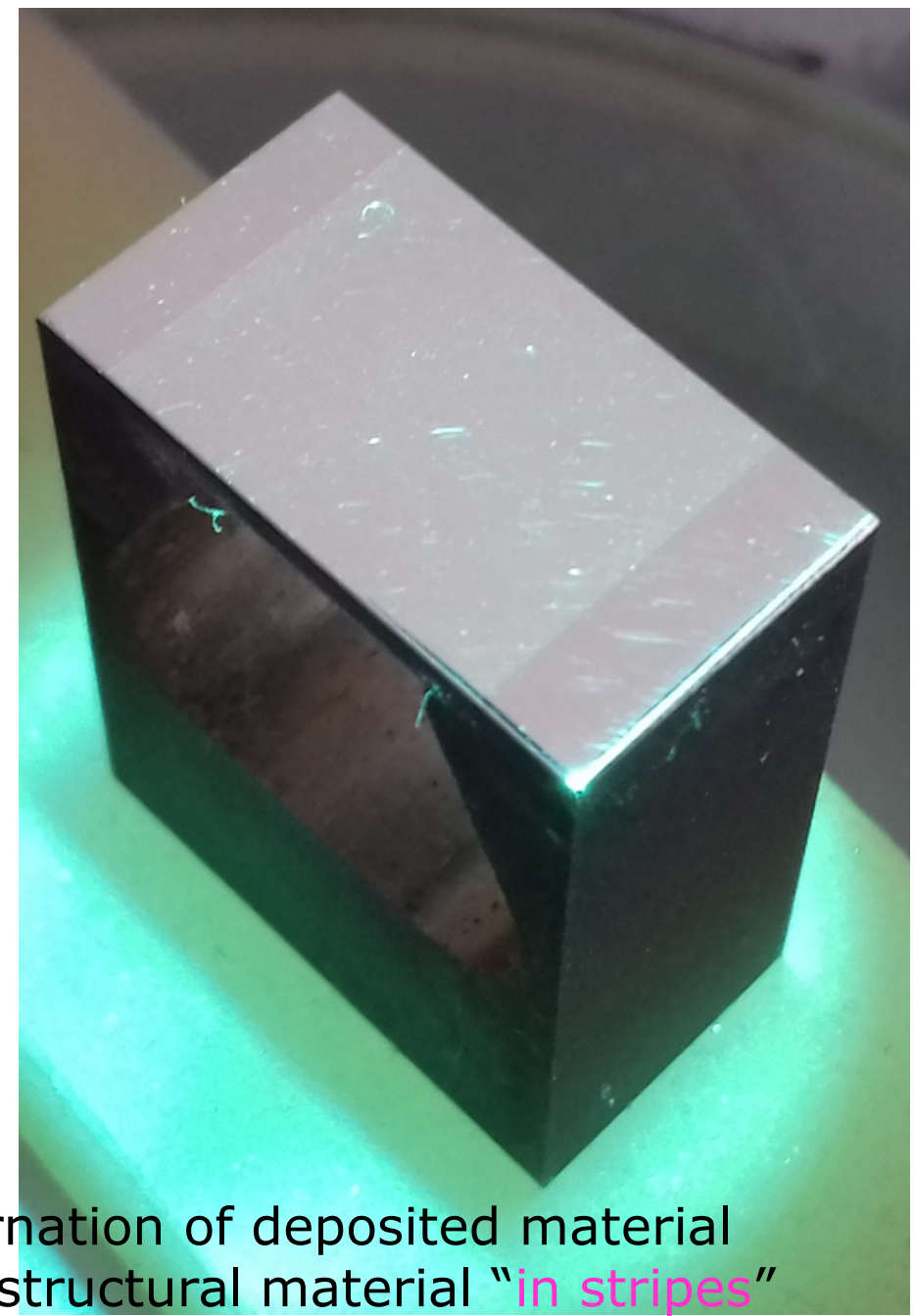

Alternation of deposited material and structural material "in stripes" visible in plate surface 
- Installation of cover plate on top of channels by EB-weld

- and Diffusion welding (HIP) will be demonstrated by end of 2020

$\rightarrow$ Technology is available and parameters tested

$\rightarrow$ surface conditioning, EB and HIP process
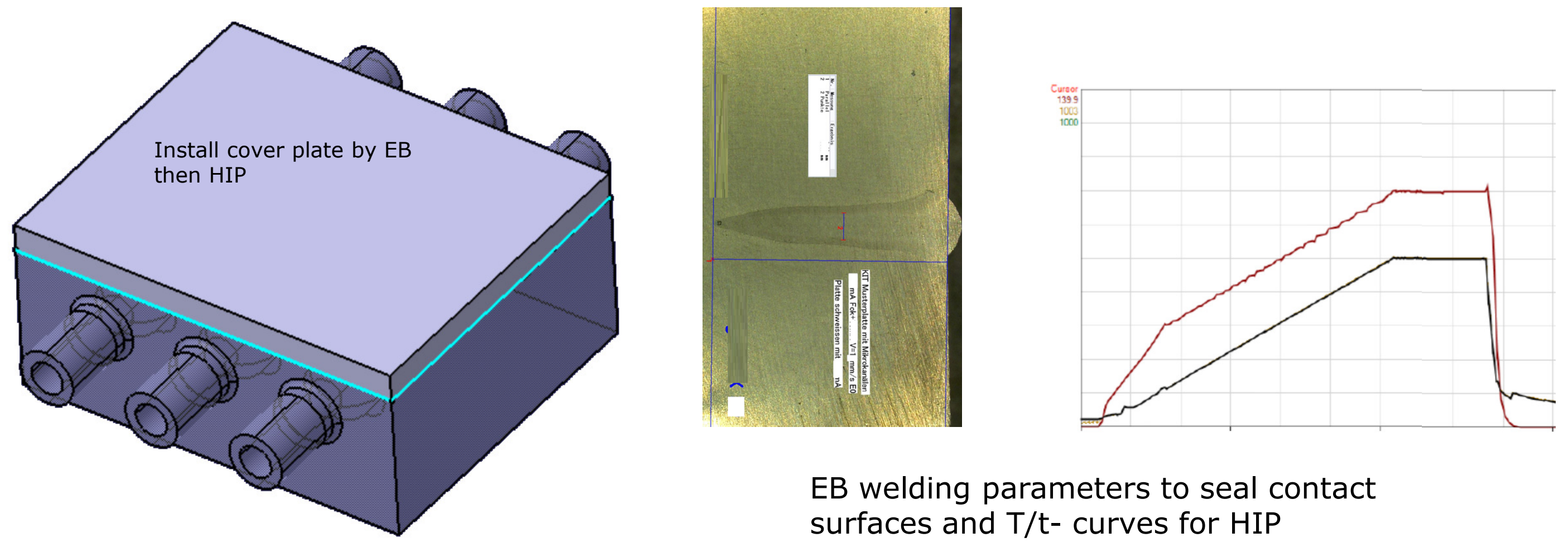

EB welding parameters to seal contact surfaces and $\mathrm{T} / \mathrm{t}$ - curves for HIP 
- Non-planar demonstration parts in medium scale are also addressed

- Two cold formed and heat treated shells are processed

$\rightarrow$ CS deposition is planned by end 2020

$\rightarrow$ Fabrication of the cover plate +

$\rightarrow$ EB and HIP for installation of the cover plate is planned in 2021
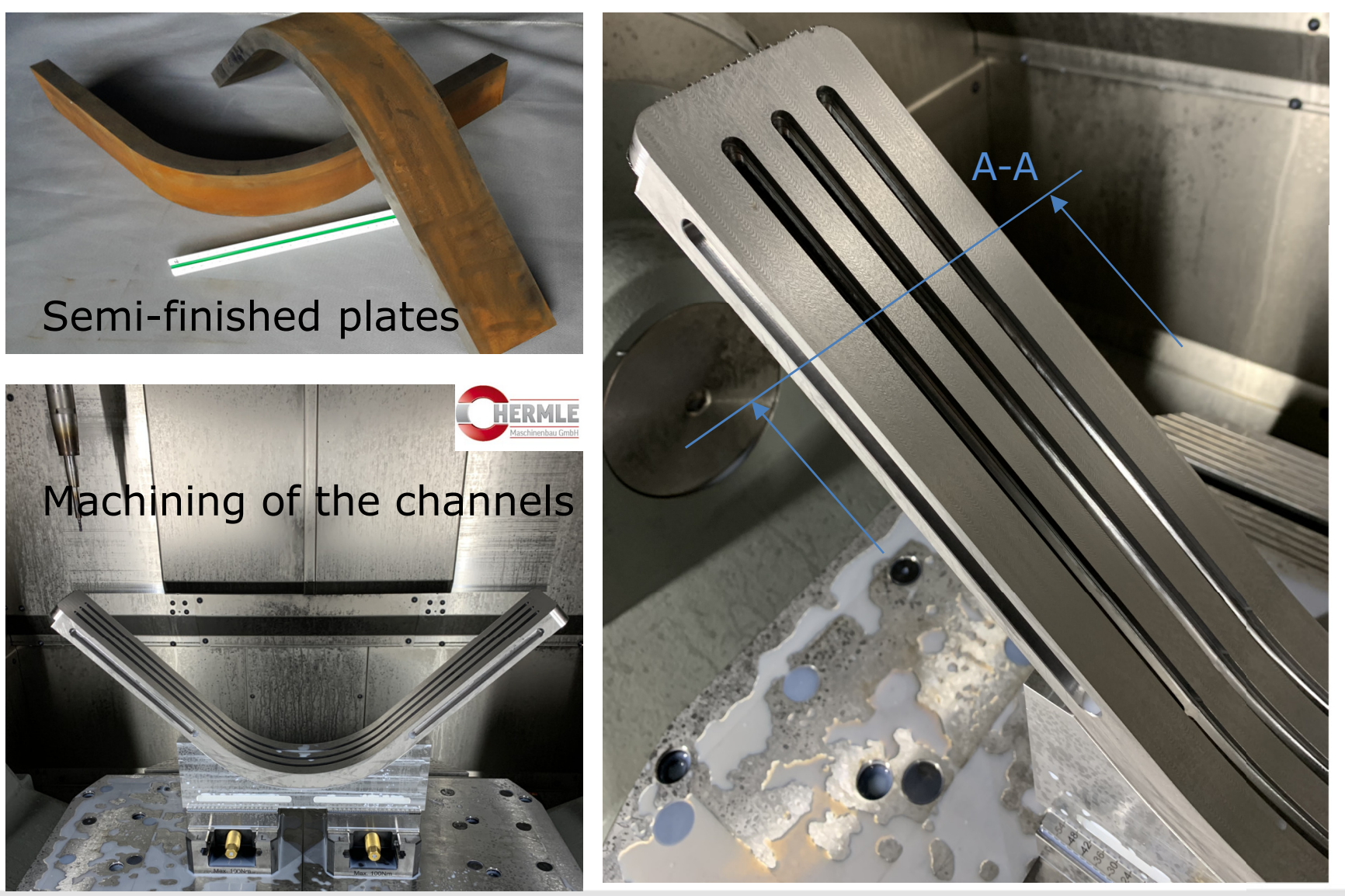

HTE-structures are included:

- 1 smooth,

- 1 laser structured

- 1 with semi detached ribs Parts used in experiments
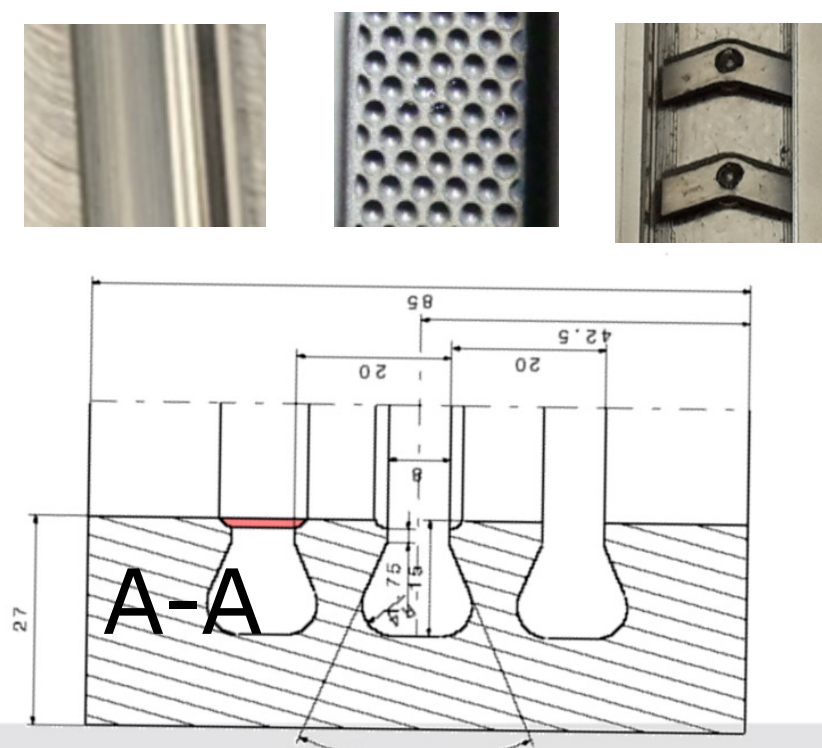
- Spherical shell segment: Origin: machined from full

$\rightarrow$ Machining and deposition are planned by end 2020

$\rightarrow$ Machining of cover plate + EB + HIP in 2021

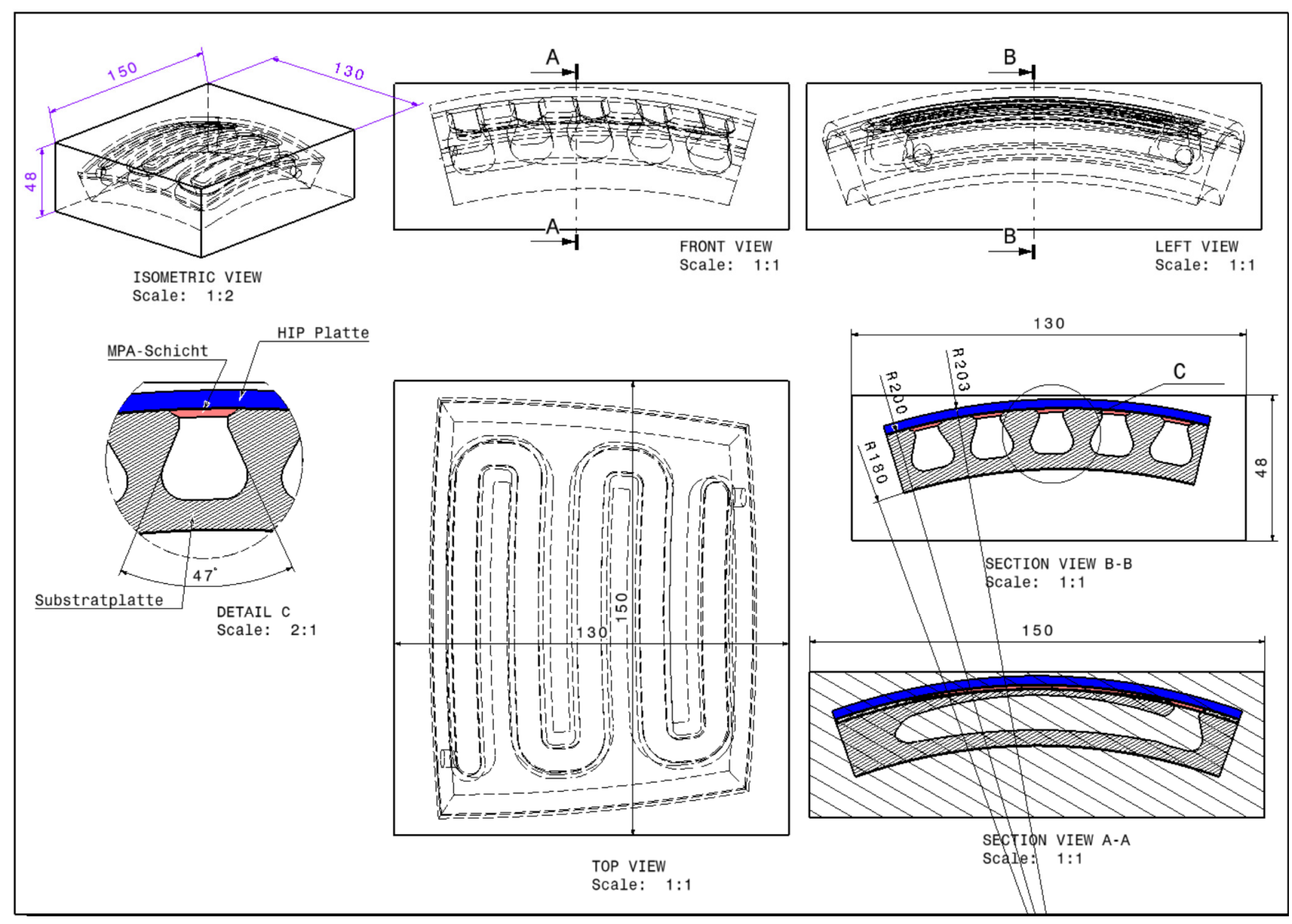

Specifications:

- $130 \times 150 \mathrm{~mm}^{2}$

- One meandering channel

- Smooth channel internal surface 


\section{Mid-term demonstrators by end of conceptual phase $\rightarrow$ 2024:}

- Use max. dimensions of available equipment, has to fit into CS machine (a)

- Both Shells (substrate + cover) machined from the full

- Channel Cross section will be FW relevant (b)

- Shape will be relevant but scaled down (c)

- Three identic parts are built for NDE, DE and testing

- Qualification procedures will be addressed

- Notified bodies will be involved to agree licencing aspects
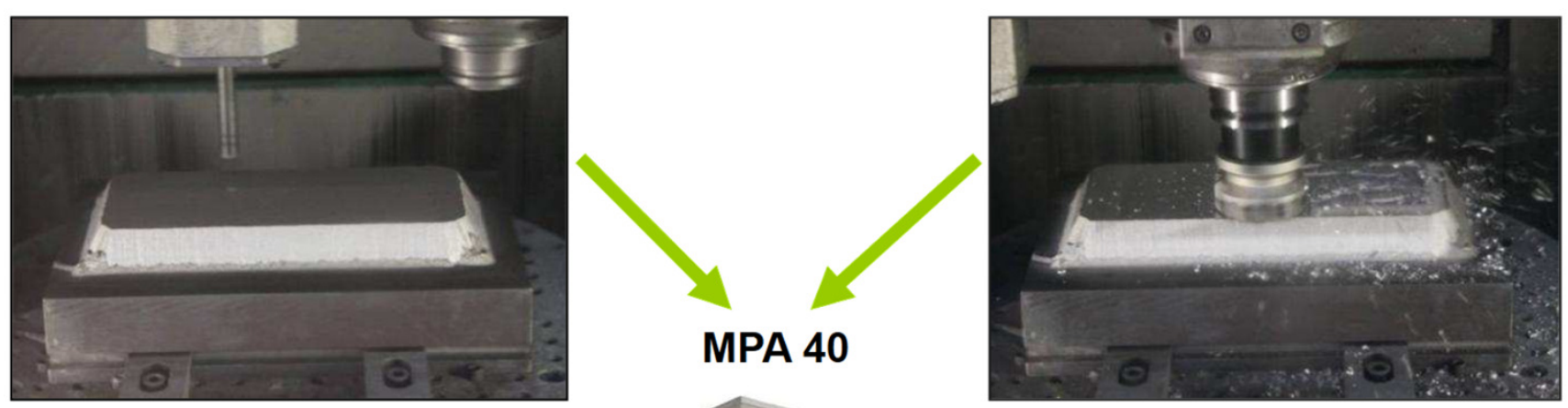

http://werkstoffwoche. de/fileadmin/user uplo ad/Hermle Praesentati on Additive Fertigun g mit der MPA Techn ologie.pdf
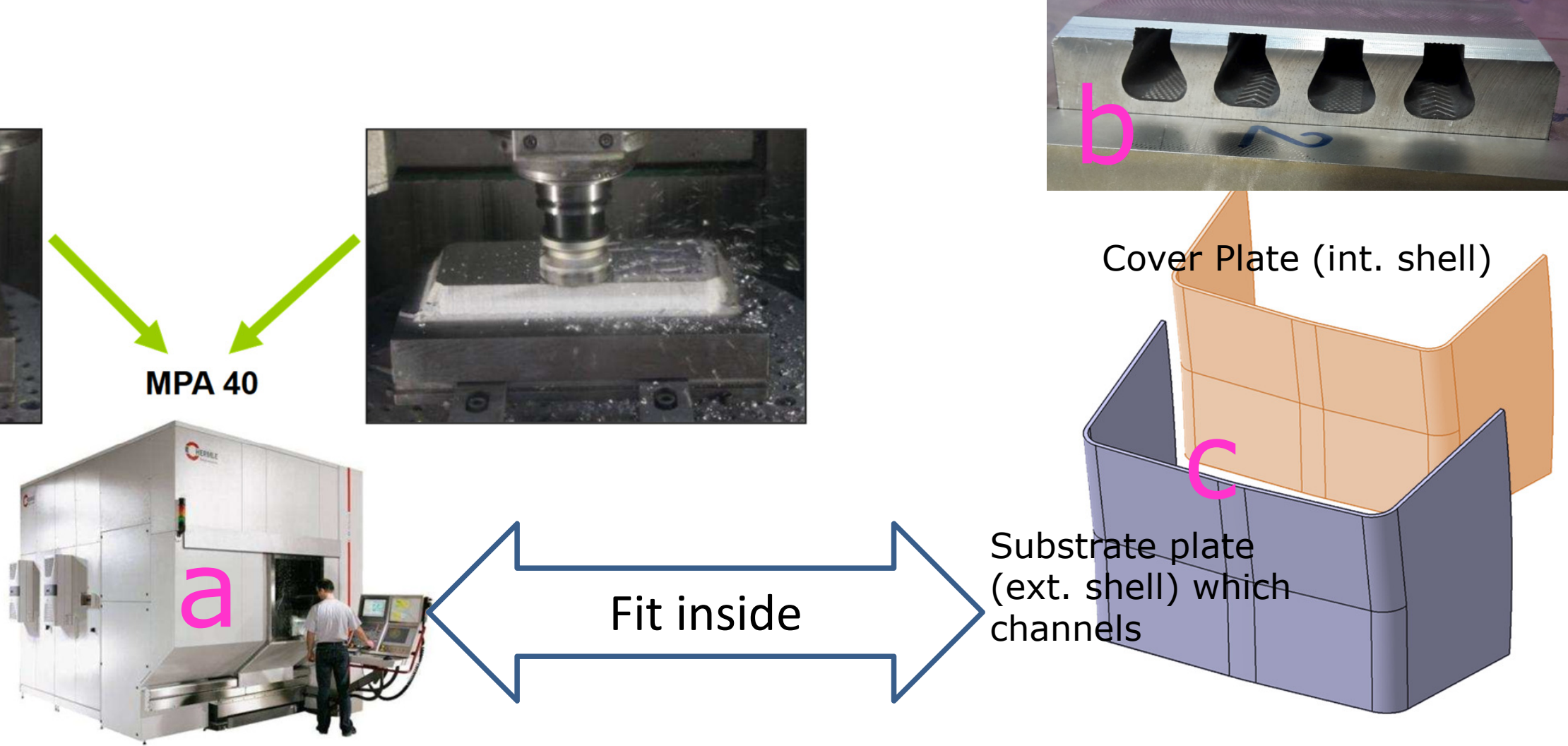


\section{Strategy towards full scale First Wall $\mathbf{V M}$ \\ Defined beyond 2027 (if CS + HIP demonstrated successfully)}

- Adapt integral process setup towards full scale serial production

- In terms of Cold Spray + machining:

$\rightarrow$ Use portal machines, comparable equipment exists e.g. in shipbuilding

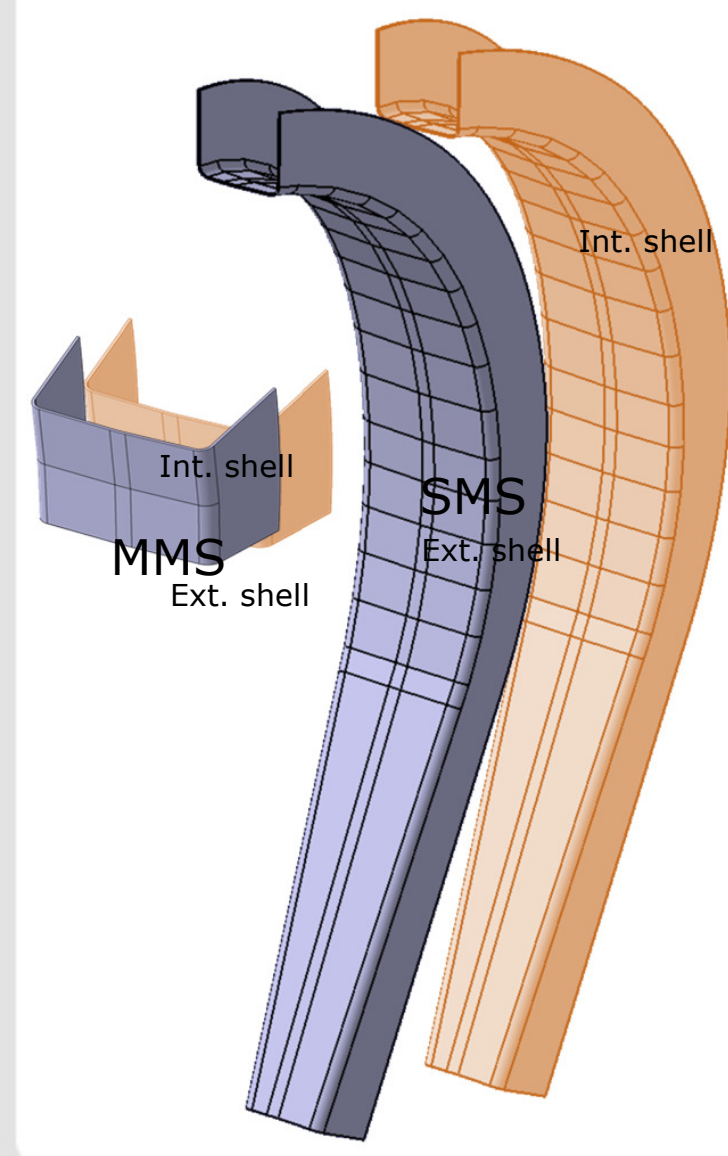

- Machining of full scale BB First Wall in MMS configuration

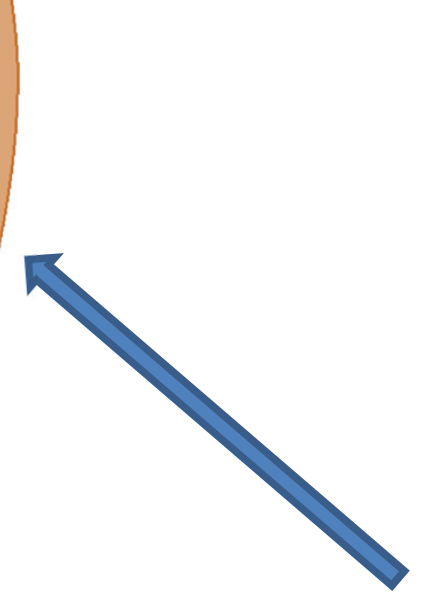

- But where do the semi-

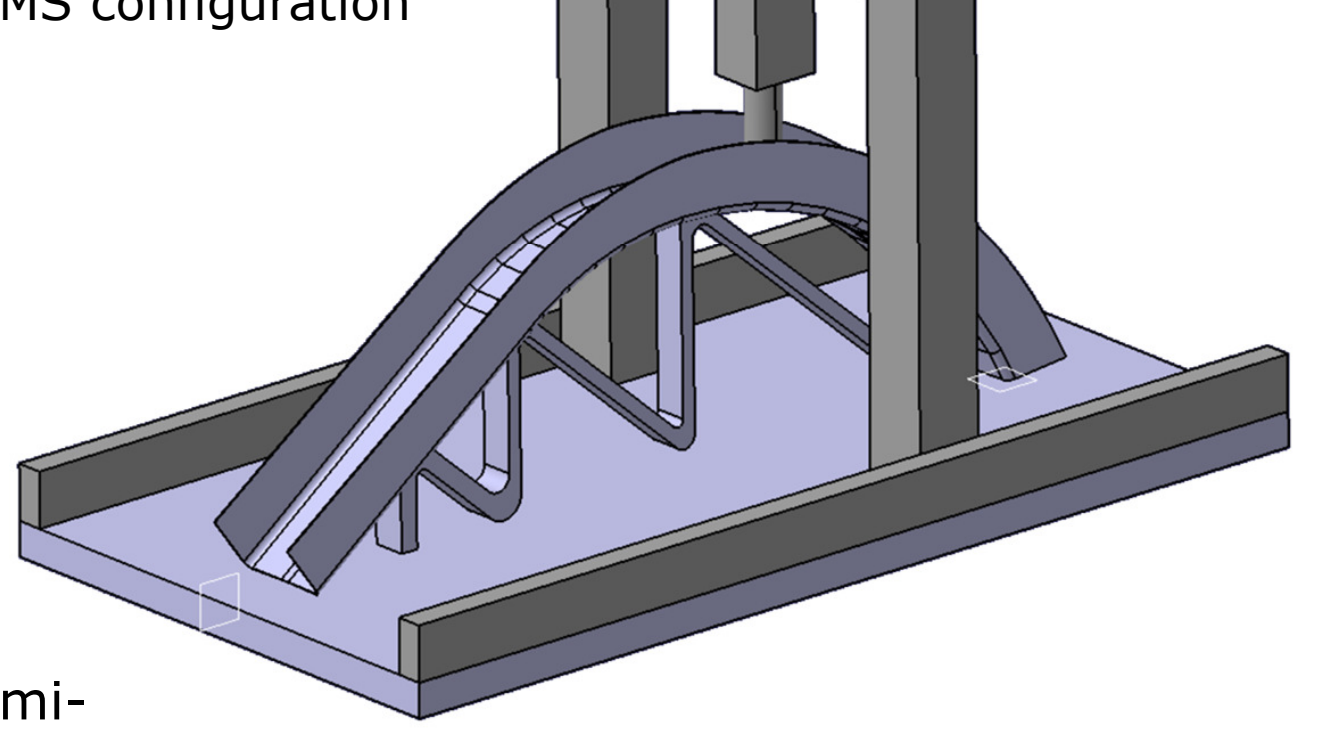
finished substrate + cover plate come from ? 


\section{Problems in procurement of full scale semi finished FW shells}

- Machine SMS shells from full $\rightarrow$ block with $12 \times 2 \times 5 \mathrm{~m}^{3}=\sim 1000 \mathrm{t}$

- Apply forming from sheets will significantly exceeded limits for MMS (even for SMS)

$\rightarrow$ Apply experiences in forming for TBM,

$\rightarrow$ Extrapolate the numbers for TBM and BB development

$\rightarrow$ Neither free bending nor deep drawing provide solutions
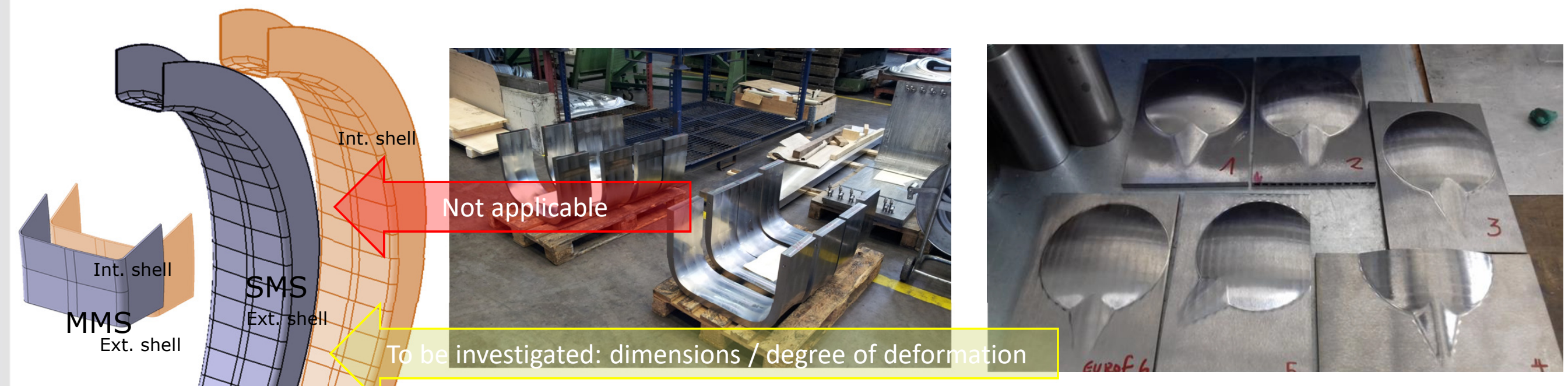

- $\quad$ Forging may provide alternatives $\rightarrow$ reduce forces $\rightarrow$ investigate

- However similar size and handling limits remain

- Maybe more „Additive Manufacturing" can provide an alternative ? 
High deposition rate cladding (also an AM-process) may be an optíon

- To be considered to building of semi finished Breeder Blanket First Wall shells

- In SMS full scale dimensions and complex geometry

- How does it work?

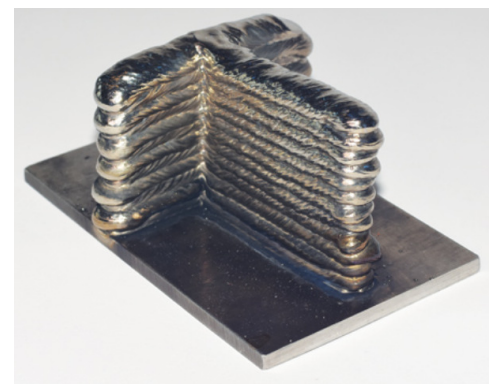

$\rightarrow$ Build up a part by ADDING layer by layer using conventional welding technology (e.g. TIG)

$\rightarrow$ Deposition is applied in alternation with machining to build precise external contours

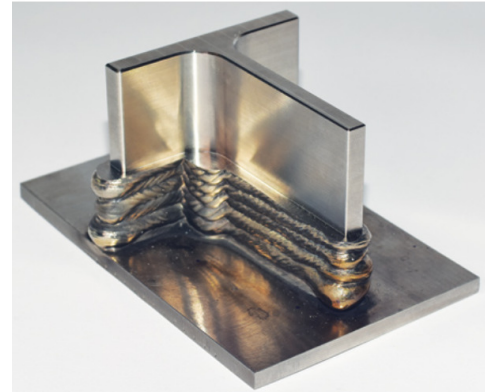

$\rightarrow$ technology may be an option for production of semifinished solid FW shells

$\rightarrow$ Shells can be processed used CS + HIP routine described before

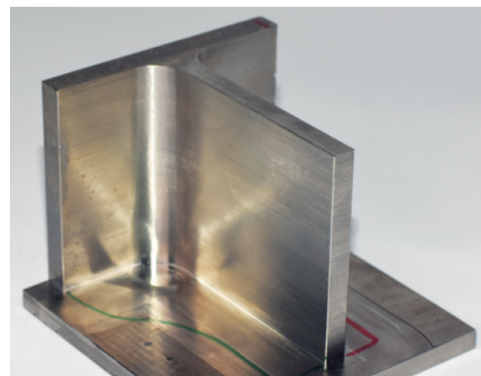

$\rightarrow$ However: Welding on the plasma facing side ! 


\section{Conclusions}

- Many key issues are still not solved, not only in fabrication

- There is not "the one" process covering all requirements for a fusion BB

$\rightarrow$ Neither AM nor conventional technologies

- But: Additive Manufacturing provides new opportunities and aspects

$\rightarrow$ Cold Spray as customized AM process $\rightarrow$ promising for the First Wall

$\rightarrow$ Selective Laser Melting applied for BB internal structures

$\rightarrow$ Important to combine all existing technologies wisely to overcome limits and create new opportunities

- Licensing and material properties verification remain the key issue

$\rightarrow$ To be addresses by material science 